\title{
Effect of a Functional Training Program on Some Physical Variables and Bone Mineral Density in Injured with Lumbar Arthritis
}

\author{
Hisham Gomaa Elkersawy ${ }^{1}$ \\ ${ }^{1}$ Lecturer, Biological Sciences \& Health Sports Department - Faculty of Physical Education - Almenofia University - Egypt
}

\begin{abstract}
This research aimed to identifies the effect of a functional training program on some physical variables(Back flexibility, back strength, Range of motion, the trunk flexion, Range of motion the trunk extension, pain Feeling, Balance) and bone mineral density (BMD (L5-L4) , BMC (L5-L4), Femur bone density, BMD. F.N, Density of hip bone, hip bone BMD.Tro, neck BMC F.N, rotation BMC.Tro) in those injured with lumbar arthritis. The researcher used the experimental approach using an experimental group and a control group, using pre and post measurements, The sample of the research was chosen purposely, the sample consisted of (12) males (15:20) years, and were divided into two groups, the experimental group consisting of (10) injured and applied to them the functional training program, and control group consisting of (10) injured who were treated with the hospital's treatment program. The researcher recommend with The importance of periodic medical examination regularly to observe any changes in the anatomical and morphological aspects of the spinal column and early detection of any shortcomings or injuries that may be exposed to the person, Guided by The functional training program and the generalization of its use in centers and Rehabilitation institutions and hospitals, Spreading cultural awareness of community members towards the early detection of low back pain cases to prevent the progression of infection to advanced grades, Continue to perform exercises and exercise, which works to maintain muscle strength and flexibility even after the completion of the proposed program.
\end{abstract}

Keywords: functional training program, bone mineral density, lumbar arthritis .

\section{Introduction and Problem of Research:}

$\mathrm{T}$ The rapid progress in sports is a reflection of the great development that is taking place in the field of science related to sport education, Any development or progress in any field will undoubtedly contribute to the development and modernization of the sciences of physical education and sport, This is reflected in the development of sports training methods that contribute to the progress of our players in all sports activities are different, In recent decades sports have witnessed a great leap that has made the limits of human capabilities rise to achieve figures that in the past were pure imagination.

lumbar arthritis occurs as a result of some underlying psychological disorders and underlying microbial diseases, and transient or persistent life pressures, whether family, social or occupational, and the incidence of lumbar arthritis may end with serious complications different from one person to another, but it begins to appear successively as the injury progresses, These complications are difficult to stand up and walk and occur as a result of the fusion of the joints of the vertebrae, which leads to a lack of flexibility in the spine, which leads to difficulties while standing and walking and thus affects the activities the usual daily of the injured .(25)

lumbar vertebrae are the most vertebrae which bear body weight, They are five vertebrae in the lower back, in addition to being affected by excessive pressure and wrong handling with the body muscles, so it is one of the most vertebrae in the spine that is prone to infection, In acute pain in the lower back causes the back curvature and difficulty of movement, and affects the joints and knees and pelvic area of the spine, and unlike other back vertebrae, the lumbar spine arthritis develops slowly and the patient suffers severe pain when waking up after a long period of exposure to the body of rest, inactivity and movement.(9: 99)

a large percentage of persons suffer from back pain in the lumbar, despite this progress in the field of medicine and diagnosis, especially sports medicine, the pain of the lumbar continues to threaten many persons, The first step is to control these pains The person has the right decision to be physically correct, The spine is in dire need of 
consecutive day care even if the persons does not suffer the pain of the lumbar, despite the importance of treatment, whether through drugs or hand therapy, Physical exercises are the best ways to keep back healthy.(7:115)

the lumbar infection affects a person of approximately 3000 people, and the age range of 15 to 40 years is the most susceptible to infection, the percentage of males rises at a rate of 9 times more compared to females, and the incidence of lumbar arthritis is more influential in the spinal joints, especially the ones that fall below the spine, but the complications of the injury can infect other joints in the body, especially the iliac joint.(20: 98)

the causes of lumbar arthritis is exposure to a sudden accident such as a car accident or a fall accident and others, severe psychological pressures that lead to cramps and cramps in the vertebrae, the wrong daily activity that affects the lumbar vertebrae with severe inflammation, and osteoporosis of the most causes leading to lumbar inflammation, obesity and progression in pregnancy months that cause pressure on back vertebrae due to increased fetal weight, some diseases such as renal colic, urethral and bladder inflammation, ovaries, and uterine cramps.(21: 72)

the symptoms of lumbar infection are the feeling of acute pain in the lower back, as well as headaches, inability to bend back and normal activities, feeling pain when sleeping and feeling sick, feeling pain under the foot, breathing disorder as a result of preventing the expansion The rib cage is healthy when breathing, and the damage to the heart is caused by inflammation at the site of the valves which leads to the deficiency and inflammation of the aortic valve (aorta), and the injured of the inflammation of the paragraphs of the cause of recurrent pulmonary infections.(26)

bones form the main body pillar in the face of gravity and help to stand up and move, if the person was younger and more active, then the cell more active regeneration and the more recently produced bone tissue than what the body may lose, and in general the bone mass of bone peak at the age of about thirty, the body then begins loss of bone density gradually with age as a result of the associated lack of movement and activity.(13: 8)

development of the skeletal structure and the efficiency of carrying out its duties in the child is an important influence on physical maturity, $\mathrm{He}$ adds that the importance of the bones is that it provides the process of connecting the joint, cartilage and ligaments and forms the general structure of the body. In protecting the soft tissue and being a huge and important store of calcium and phosphorus, and the stock of calcium and phosphorus in blood involved in the formation of blood cells.(16:52)

calcium is the most important mineral in the human body, with calcium from $1.5 \%$ to $2 \%$ of body weight, and $39 \%$ of the body's minerals, about $99 \%$ of which are concentrated for a quantity in the bones and teeth, the remaining $1 \%$ in the blood and cells of the body where they perform important metabolic functions, and the concentration of calcium in the blood plasma is accurately adjusted between $8.8 \mathrm{mg} / \mathrm{dl}$, and the importance of its ability to maintain balance in the mineral elements and conservative on the acidic and alkaline acid balance of the lung and kidney $\cdot(15: 123)(10: 957)$

Sports training is an important factor in the success of athletes in achieving their objectives of training and sporting activity, and the functional sports training is a specialized system of sports training depends on the training of a group of muscles without focusing on the training of person muscles, and the training offered is diversified with the aim of exercise the whole body in a consistent and integrated framework, and the exercise varies in the functional sports training system where it includes several forms of sports activity in which the person varies between high intensity exercise and short exercise and in a thoughtful way helps the athlete to achieve maximum effectiveness of training performance Sports.

functional exercises are integrated, multi-level, transverse and cross-sectional movements that include acceleration, fixation, and deceleration, with the aim of improving the kinetic power, the central strength of the spine, the middle of the body, and the nerve and muscular efficiency, and the functional strength exercises are a combination of muscular strength drills and balancing exercises lead to consistent and harmonious timing.(6: 46)

the professional sports training focuses on intensive exercises that achieve the highest number of sporting goals in the least time possible and helps to stimulate body metabolism and burn accumulated fat in body parts and strengthen the heart and muscles, In addition to the sense of self confidence and skill and high level of neuromuscular endurance and agility and speed with the feeling of strength and ability to do more energy and achieve flexibility and balance for a large proportion of muscle groups.(24: 44)

Athletic career training achieves the decency to enable the person to perform many daily and athletic movements in a manner that is characterized by skill and accuracy, and 
depends on the ability of the person to perform many sports activities naturally diverse, which include walking, running, rotation, wrapping and movement Fast, slow and more, with the use of appropriate sports tools, the person can access athletic skills to the highest levels, leading to higher strength, increased flexibility of joints, improved balance, effective body weight, muscular alignment, and bone and muscle strengthening.(23:112)

the functional training is characterized by characteristics and features, the most important of which is to focus on the group of muscles of the center responsible for adjusting the balance, the multiplicity of motor levels, the multiplicity of joints involved in performance, the development of the ability to control the anti-equilibrium, and the improvement of the motor characteristics of one party or over the top of both sides or inferior, improve the integrative movement, ability and speed of the specialist sports activity.(12: 24)

Through access to the international information Network (Internet), the researcher noted the recent use of functional training in the face of damage and problems resulting from exposure to injuries, whether for ordinary persons or athletes, and studies on the effects of functional training on physical aspects the physiological and synthesis of salts and bone minerals of young and adult players differed in their results, prompting the researcher to conduct this study to learn about the impact of a program of functional exercises on some physical variables and bone and spine minerals in those with lumbar inflammation.

\section{Research Objective:}

This research aimed to identifies the effect of a functional training program on some physical variables and bone mineral density in those injured with lumbar arthritis.

\section{Research hypotheses:}

The functional training program positively affects on some physical variables and bone mineral density in those injured with lumbar arthritis.

\section{Research procedures:}

- Methodology: The researcher used the experimental approach using an experimental group and a control group, using pre and post measurements.

- Sample: The sample of the research was chosen purposely, the sample consisted of (12) males (15:20) years, and were divided into two groups, the experimental group consisting of (10) injured and applied to them the functional training program, and control group consisting of (10) injured who were treated with the hospital's treatment program .

Table (1)

Research sample description $(\mathrm{N}=12)$

\begin{tabular}{|c|c|c|c|c|c|}
\hline Variables & unit & Mean & Standard deviation & Median & skews \\
\hline Age & year & 16.10 & 1.20 & 16.00 & $0.122-$ \\
\hline Length & $\mathbf{c m}$ & 170.70 & 8.07 & 171.00 & $0.193-$ \\
\hline Weight & $\mathbf{k g}$ & 66.20 & 6.25 & 63.00 & 0.161 \\
\hline Patient History & year & 3.45 & 1.65 & 3.42 & 0.150 \\
\hline
\end{tabular}

Table (1) show the Skews of the research sample was limited to $( \pm 3)$ in the variables under study, indicating the homogeneity of the research sample.

The researcher found the equivalence between the two groups of research (experimental - control) using (T. test) for the variables under consideration as shown in Table

\section{Equivalence of the research sample:} (2). 
Table (2)

Equivalence between the two groups (experimental - control) in search variables $(\mathrm{N} 1=\mathrm{N} 2=12)$

\begin{tabular}{|c|c|c|c|c|c|c|c|}
\hline \multirow{2}{*}{ Variables } & \multirow{2}{*}{ Unit } & \multicolumn{2}{|c|}{ experimental group } & \multicolumn{2}{|c|}{ Control group } & \multirow{2}{*}{$\begin{array}{c}\text { Aver } \\
\text { different }\end{array}$} & \multirow{2}{*}{$\begin{array}{c}\text { T } \\
\text { value }\end{array}$} \\
\hline & & $\mathbf{M}$ & $\pm Z$ & M & $\pm Z$ & & \\
\hline Back flexibility & cm & 5.12 & 0.12 & 5.22 & 0.15 & -0.1 & 0.58 \\
\hline back strength & kg & 71.05 & 4.23 & 70.15 & 4.21 & 9.0 & 0.13 \\
\hline $\begin{array}{l}\text { Range of motion } \\
\text { the trunk flexion }\end{array}$ & $\mathrm{cm}$ & 46.60 & 3.975 & 47.00 & 4.472 & -0.4 & 0.64 \\
\hline pain Feeling & degree & 9.12 & 0.04 & 9.10 & 0.14 & -0.2 & 0.32 \\
\hline Balance & sec & 57.55 & 5.29 & 52.65 & 5.23 & 4.9 & 1.16 \\
\hline
\end{tabular}

$\mathrm{T}$ Value significant level of $0.05=2.30$ and at $0.01=3.35$

Table (3) shows that calculated values are less than tabular values, indicating the equivalence of the two research groups in the variables under study, as well as the absence of statistically significant differences at a significant level of 0.05 in the basic variables between the experimental group and the Indicates the equivalence of the two research groups.

\section{Research fields:}

- Human field: (12) male injured with lumbar arthritis who are reluctant to the physiotherapy and rehabilitation unit at Tanta University Hospital.

- Geographical area: Tanta university stadium and ElShifa Center for Physiotherapy.

-Time period: $1 / 5 / 2018$ to $30 / 7 / 2018$.

\section{Data collection and tools:}

The researcher has read the Arabic and English References, scientific research and the World Wide Web.

\section{Functional training program}

-The proposed program has been divided into three phases, each stage lasts 15 days and each stage has a set of exercises that vary in intensity and size to suit the development and improvement of the situation .

- Training is done 4 days a week and the training unit lasts from 30 to 45 minutes in addition to the intervals of comfort, with the possibility of two days of passive rest and breaks vary from one case to another depending on the intensity of the exercise and the extent of pain.

\section{Research Measurements:}

Height measurement: using Restameter.

Weighting: using medical scale.

Measuring strength: using Dynamometer.

Measurement of the motor range of the back: by bending the trunk front test , and bending the trunk back test .

Measuring the range of the lumbar vertebrae : by genometer .

Measuring balance: By testing the stand on the instep.

Measuring pain level: using Visual analogues Scales.

\section{- Tools and devices used in Research:}

The researcher used the following tools and devices: Electronic medical balance, Balances of different weights , Boxes with different, heights, Medical balls of different weights ,Soccer balls , cones, ropes , Medical ball weight (3-5-7 kg), Swiss balls (ball bearings) ,Rubber antistatic , Stop Watch, DEXA (Double Energy X-ray) by Norland in the Department of Radiology at the Faculty of Medicine Hospitals.

\section{- Statistical analysis:}

The researcher used the SPSS program to conduct the following statistical transactions, Arithmetic mean, Median , Standard deviation, skews, T Test to denote statistical differences, coefficient of change rates of averages.

\section{Results:}


Table (3)

Indication of differences between the post and pre measures of the control group In physical variables $(N=6)$

\begin{tabular}{|c|c|c|c|c|c|c|c|}
\hline \multirow{2}{*}{ Variables } & \multirow{2}{*}{ Unit } & \multicolumn{2}{|c|}{ Post measures } & \multicolumn{2}{|c|}{ Pre measures } & \multirow{2}{*}{$\begin{array}{c}\mathbf{T} \\
\text { value }\end{array}$} & \multirow{2}{*}{)$\%($} \\
\hline & & $\mathbf{M}$ & $\pm Z$ & $\mathbf{M}$ & $\pm Z$ & & \\
\hline Back flexibility & $\mathbf{c m}$ & 5.12 & 0.12 & 12.58 & 0.41 & $* 5.34$ & 21.82 \\
\hline back strength & kg & 71.05 & 4.23 & 82.31 & 7.76 & $* 4.11$ & 31.43 \\
\hline $\begin{array}{l}\text { Range of motion } \\
\text { the trunk flexion }\end{array}$ & $\mathbf{c m}$ & 46.600 & 3.975 & 85.200 & 1.643 & $* 5.35$ & 27.45 \\
\hline $\begin{array}{l}\text { Range of motion } \\
\text { the trunk extension }\end{array}$ & $\mathbf{c m}$ & 23.800 & 1.924 & 28.400 & 0.894 & $* 6.27$ & 30.45 \\
\hline pain feeling & degree & 9.12 & 0.04 & 2.94 & 0.02 & $* 10.71$ & 29.45 \\
\hline Balance & sec & 57.55 & 5.29 & 64.35 & 2.48 & 8.83 & 30.80 \\
\hline
\end{tabular}

The value of $T$ in table at a significant level of $0.05=2.26$

Table (4)

Indication of differences between the post and pre measures of the experimental group in physical variables $(N=6)$

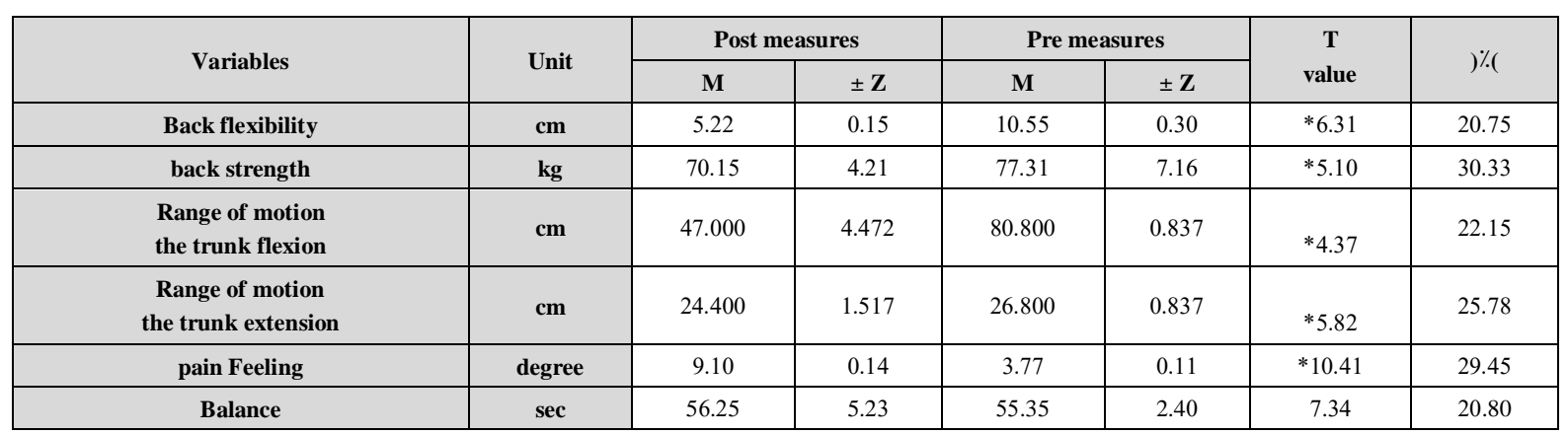

The value of $T$ in table at a significant level of $0.05=2.26$

Table (5)

ANCOVA between averages in pre measures of the control and experimental group In physical variables

\begin{tabular}{|c|c|c|c|c|c|}
\hline variables & Source & Degree freedom & Total squares & Average squares & Value "P" \\
\hline \multirow{3}{*}{ Back flexibility } & Difference between groups & 2 & 10.31 & 5.155 & \multirow{3}{*}{$* 2.8$} \\
\hline & Intra-group variation & 12 & 38.82 & 1.84 & \\
\hline & total summation & 14 & 49.13 & & \\
\hline \multirow{3}{*}{ back strength } & Difference between groups & 2 & 8.73 & 4.36 & \multirow{3}{*}{$* 3.15$} \\
\hline & Intra-group variation & 12 & 29.14 & 1.38 & \\
\hline & total summation & 14 & 37.87 & & \\
\hline \multirow{3}{*}{$\begin{array}{l}\text { Range of motion } \\
\text { the trunk flexion }\end{array}$} & Difference between groups & 2 & 11.02 & 5.51 & \multirow{3}{*}{$* 3.44$} \\
\hline & Intra-group variation & 12 & 33.62 & 1.6 & \\
\hline & total summation & 14 & 44.64 & & \\
\hline \multirow{3}{*}{$\begin{array}{c}\text { Range of motion } \\
\text { the trunk extension }\end{array}$} & Difference between groups & 2 & 7.66 & 3.83 & \multirow{3}{*}{$* 2.91$} \\
\hline & Intra-group variation & 12 & 27.53 & 1.31 & \\
\hline & total summation & 14 & 35.19 & & \\
\hline \multirow{3}{*}{ pain Feeling } & Difference between groups & 2 & 6.52 & 3.26 & \multirow{3}{*}{$* 2.69$} \\
\hline & Intra-group variation & 12 & 25.49 & 1.21 & \\
\hline & total summation & 14 & 32.01 & & \\
\hline \multirow{3}{*}{ Balance } & Difference between groups & 2 & 5.200 & 2.600 & \multirow{3}{*}{0.315} \\
\hline & Intra-group variation & 12 & 99.200 & 8.267 & \\
\hline & total summation & 14 & 104.400 & & \\
\hline
\end{tabular}


Table (6)

Indication of differences between the post and pre measures of the control group In bone density and mineral variables $(\mathrm{N}=6)$

\begin{tabular}{|c|c|c|c|c|c|c|c|}
\hline \multirow{2}{*}{ Variables } & \multirow{2}{*}{ Unit } & \multicolumn{2}{|c|}{ Post measures } & \multicolumn{2}{|c|}{ Pre measures } & \multirow{2}{*}{$\begin{array}{c}\mathbf{T} \\
\text { value }\end{array}$} & \multirow{2}{*}{)$\%($} \\
\hline & & $\mathbf{M}$ & $\pm \mathbf{Z}$ & $\mathbf{M}$ & $\pm \mathbf{Z}$ & & \\
\hline $\begin{array}{l}\text { Spinal Bone mineral density BMD (L5- } \\
\text { L4) }\end{array}$ & $\begin{array}{c}\mathrm{gm} / \mathrm{cm} \\
2\end{array}$ & 0.639 & 0.06 & 0.802 & 0.04 & $* 11.78$ & 25.05 \\
\hline $\begin{array}{c}\text { Spine Bone mineral Content BMC (L5- } \\
\text { L4) }\end{array}$ & gm & 21.07 & 3.59 & 25.07 & 2.75 & 11.59 & 18.17 \\
\hline $\begin{array}{l}\text { Femur bone density } \\
\text { BMD. F.N }\end{array}$ & $\begin{array}{c}\mathrm{gm} / \mathrm{cm} \\
2\end{array}$ & 0.830 & 0.05 & 0.935 & 0.02 & $* 11.45$ & 11.8 \\
\hline $\begin{array}{l}\text { Density of hip bone } \\
\text { BMD.Tro }\end{array}$ & $\begin{array}{c}\mathrm{gm} / \mathrm{cm} \\
2\end{array}$ & 0.761 & 0.03 & 0.862 & 0.07 & $* 6.76$ & 13.06 \\
\hline $\begin{array}{l}\text { Bone metal content of thigh neck BMC } \\
\text { F.N }\end{array}$ & gm & 3.71 & 0.511 & 4.57 & 0.522 & $* 12.51$ & 20.17 \\
\hline $\begin{array}{l}\text { Bone metal content of thigh rotation } \\
\text { BMC.Tro }\end{array}$ & gm & 4.58 & 1.29 & 5.46 & 0.74 & $* 13.56$ & 17.17 \\
\hline
\end{tabular}

The value of $T$ in table at a significant level of $0.05=2.26$

Table (7)

Indication of differences between the post and pre measures of the experimental group in bone density and mineral variables $(N=6)$

\begin{tabular}{|c|c|c|c|c|c|c|c|}
\hline \multirow{2}{*}{ Variables } & \multirow{2}{*}{ Unit } & \multicolumn{2}{|c|}{ Post measures } & \multicolumn{2}{|c|}{ Pre measures } & \multirow{2}{*}{$\begin{array}{c}\mathbf{T} \\
\text { value }\end{array}$} & \multirow{2}{*}{)$\%($} \\
\hline & & $\mathbf{M}$ & $\pm \mathbf{Z}$ & M & $\pm \mathbf{Z}$ & & \\
\hline $\begin{array}{c}\text { Spinal Bone mineral density BMD (L5- } \\
\text { L4) }\end{array}$ & $\mathrm{gm} / \mathrm{cm} 2$ & 0.633 & 0.12 & 0.702 & 0.11 & $* 10.28$ & 20.15 \\
\hline $\begin{array}{l}\text { Spine Bone mineral Content BMC (L5- } \\
\text { L4) }\end{array}$ & gm & 20.07 & 3.59 & 20.77 & 2.33 & 10.55 & 18.34 \\
\hline $\begin{array}{c}\text { Femur bone density } \\
\text { BMD. F.N }\end{array}$ & $\mathrm{gm} / \mathrm{cm} 2$ & 0.823 & 0.14 & 0.845 & 0.12 & $* 9.70$ & 11.34 \\
\hline $\begin{array}{c}\text { Density of hip bone } \\
\text { BMD.Tro }\end{array}$ & $\mathrm{gm} / \mathrm{cm} 2$ & 0.745 & 0.15 & 0.761 & 0.16 & $* 5.96$ & 13.78 \\
\hline $\begin{array}{l}\text { Bone metal content of thigh neck BMC } \\
\text { F.N }\end{array}$ & gm & 3.40 & 0.521 & 3.54 & 0.528 & $* 10.51$ & 18.7 \\
\hline $\begin{array}{l}\text { Bone metal content of thigh rotation } \\
\text { BMC.Tro }\end{array}$ & gm & 4.12 & 1.35 & 4.33 & 0.56 & $* 12.455$ & 14.45 \\
\hline
\end{tabular}

The value of $T$ in table at a significant level of $0.05=2.26$ 
Table (8)

ANCOVA between averages in pre measures of

the control and experimental group In bone and mineral density variables

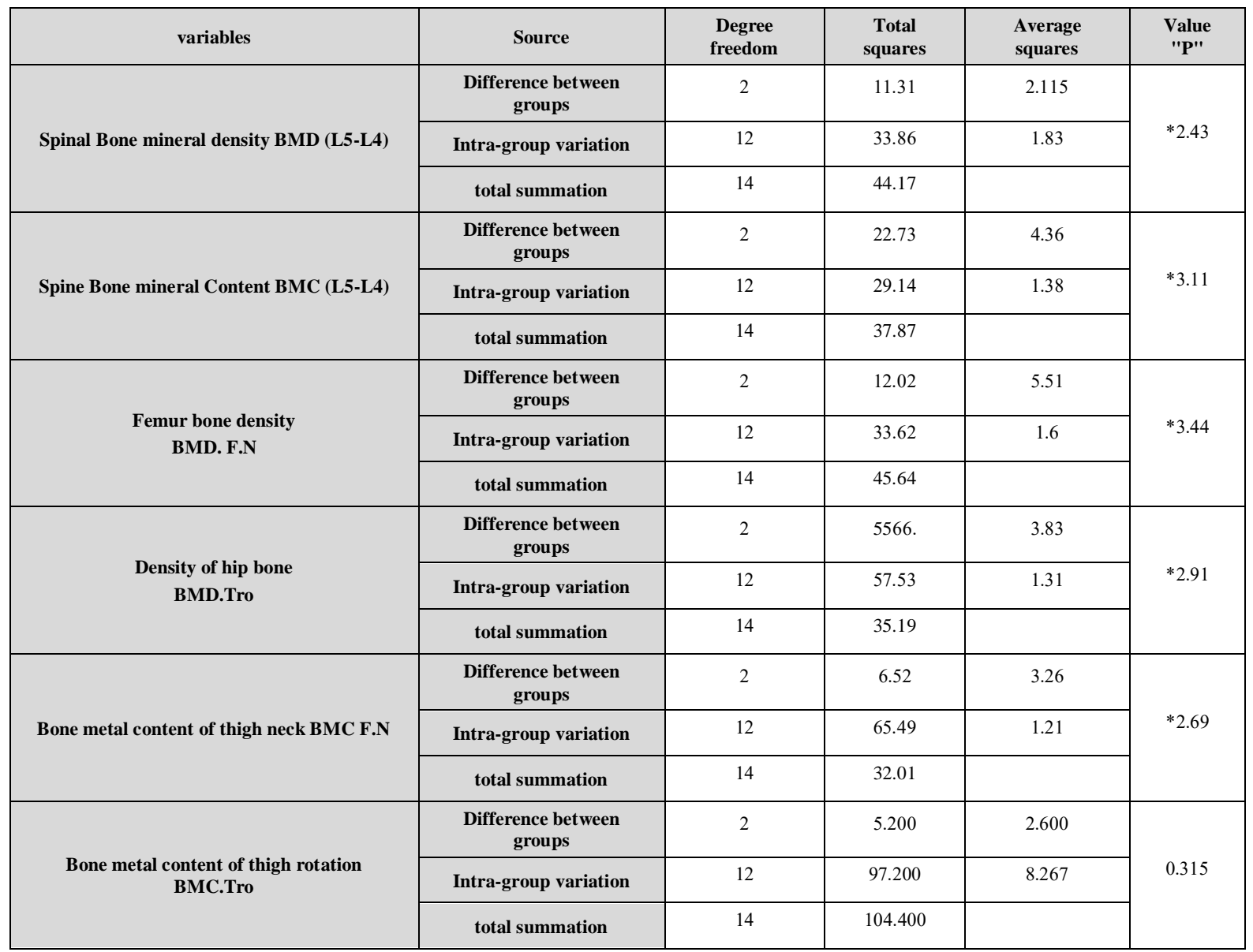

\section{Discussion of Results:}

\section{Physical variables:}

Table (3) shows statistically significant differences between the pre and post measurements of the experimental group at a level of 0.05 in some of the physical variables, and it is clear from table (4) that there are statistically significant differences between the pre and post measurements of the control group at a level of 0.05 in the variables Physical, and it is clear from table (5) that the(T) computed values are greater than the(T) tabular values, suggesting that there are statistically significant differences at the level of 0.05 in the variables between the post measurement of the experimental group.

These results are in line with the study that physical exercises in addition to functional strength training contribute to improving the physical and physiological abilities, In addition to Patient with bone injuries or inflammation of the spine(Alauddin, Samiran ,2012; Kelly et al.,2012; Amr Saber ,2012;Mustafa Atwa ,2016) .

the functional strength training works to increase the area of musculoskeletal and muscular lumbar diameter in the trained muscle by focusing on the muscles of the center, thus increasing the muscle fiber and thus increasing the amount of protein in the muscles, which leads to the acquisition of muscle tone, as confirmed by Klika \& Brett (2013) States that physical effort works to replenish and consume the full protein in the body.(3:121)(8: $2415-$ 2428)(8: 8-13)

one of the most important features of the functional training program is the emphasis on the development of the center of the body, where the strong muscles of the center bind the lower end of the upper limb, in addition to the functional training program includes multidirectional movements, and the training exercises are performed by focusing on the tip one of the best exercises used to 
improve physical abilities in addition to some physiological and morphological abilities.(21: 1458-72)

the balance is a key element in the functional exercises, not only the balance between strength and flexibility or working and non-working muscles but also the ability and effectiveness to maintain the balance of the limbs of the body a long period of time, where the person can stand on one foot and in the same time it is able to move other body parts freely without falling, this is an important interactive characteristic that is developed in the functional exercises.(12: 323-24)(26)

the muscle strength is one of the most important physical elements needed by athletes, because all movements depend on how the body moves, the muscles control this movement by contraction and expansion from one place to another . (18:22)(19:45)

when the muscles are stronger it will be more effective and efficient these contractions, and this is consistent with the results of (Kelly et. al.,2012) that the training programs of functional power aims to guide the strength resulting from the performance of sports, and performs in the movements of multi-level and integrated and do not rely on external stabilizers through the devices and tools, but use the backbone to facilitate movement as a tool to support and install.

\section{2- Bone mineral density variables:}

Table (6) shows that there are statistically significant differences between the pre and post-experimental parameters of the experimental group in the density and content variables of the bone minerals in favor of postmeasurement, as shown in Table (7), There are no statistically significant differences between the pre and post measurements of the control group in density variables (8) showed significant differences at 0.05 level between the experimental group and the control group in the density and bone content of the spine in dimensional measurements in favor of the experimental group

The researcher refers to the good planning of the functional training program and the legalization of training loads in a scientific manner suitable for the stage of the age and the status of the incidence of inflammation of the lumbar spine in the research sample, and to the use of biometric training as a main part in the functional training with the aim of developing the intensity and the content of bone minerals, here comes the importance of exercising and regularly, as it helps to build and strengthen muscles and give the body the flexibility and poise necessary to facilitate its movements.
These results are consistent with the study however the selection of weight training within the functional training program should receive attention as it improves the density and content of bone minerals. It also improves muscle neuromuscular performance, improves physical efficiency and is a good preparation of the athlete for training and competition requirements(Rizzoli , 2012; Alauddin \& Samiran ,2012; Kelly et. al., 2012).(31)(1: 0105)(11: 11-15)

the exercise, especially muscular strength exercises, highimpact exercises and exercise with weight-bearing exercises are essential for good bone growth, and that these exercises have nothing to do with morphological aspects related to the length The bone, however, increases the width and intensity of the bone by depositing more salts and minerals on the bones, which increasing its strength and hardness.(30)

the weight training, resistance and impact drills are the best exercises that contribute to the strength of muscles and bones, and the mechanical pressure on the bones as a result of the Physical activity regular leads to the deposition of calcium salts in bone cells, so the amount of bone building depends on the degree of strength and frequency in performance. $(2: 113)(5: 91-90)$

The researcher attributed this to the practice of physical activity in general leads to the maintenance of the density of bone minerals, and this is consistent with the results of the study of (Levrero F., Margetts L.,2016) that the practice of football for long periods especially in the preadulthood that would increase the rate of BMC, BMD for the neck thigh and spine .(14: 384-396)

the athletic activity and the level of calcium intake have an impact on the increase of bone mineral density, and that regular exercise plays a significant role in maintaining and strengthening the health of different body organs, with an internal impact that outweighs their impact In phases, where the health of the heart and arteries and the work of the lungs and others, studies have also shown the importance of sport in strengthening bones, reducing the loss of minerals, preventing osteoporosis and influencing bone density.(24: 337-44)(22: 217)

\section{Conclusions:}

Based on the researcher's findings within the limits of the research sample and the methodology used. In light of the statistical processing of these data and the scope of the research objectives, the researcher can draw the following conclusions from the discussion and interpretation of the results: 
1 - The functional training program has a positive impact on injured with lumbar arthritis of the members of the experimental group on some physical variables and bone minerals and spinal column.

2 - Diversity in the use of exercise flexibility and muscle lengthening and muscle strength exercises had a positive impact on improving the functionality of the spinal column.

3. The functional training program characterized by different methods and methods of exercise between free, weight and using the ball exercise in the program has an effective impact in improving the condition of the injured in less time and at the lowest cost.

\section{Recommendations:}

In light of the research objectives and the findings of the researcher, the following recommendations were made:

1- The importance of periodic medical examination regularly to observe any changes in the anatomical and morphological aspects of the spinal column and early detection of any shortcomings or injuries that may be exposed to the person. 2 - Guided by The functional training program and the generalization of its use in centers and Rehabilitation institutions and hospitals.

3- Spreading cultural awareness of community members towards the early detection of low back pain cases to prevent the progression of infection to advanced grades.

4- Continue to perform exercises and exercise, which works to maintain muscle strength and flexibility even after the completion of the proposed program.

\section{References:}

1 - Alauddin Shaikh, Samiran Mondal (2012) : Effect of Functional Training on Physical Fitness Components on College Male Students, Journal of Humanities and Social Science, Volume 1, Issue 2, PP 01-05.

2- Abdul Aziz Ahmed Nimr, Nariman Khatib and Atef Rashad(2001): "The impact of weight training program on the rates of improvement in muscle strength and digital levels of short distance swimmers," Scientific Journal, Faculty of Physical Education and Sports, April (37).

3- Amr Saber Hamza(2008): Effectiveness of compound training on genetic expression and some physical variables and the level of performance of the skills of challenge and attack aircraft at the origin of the duel, $\mathrm{PhD}$ thesis, Faculty of Physical Education for Boys, Zagazig University.
4(2012): Effect of work exercises on the major elements of blood and agility reaction and the level of performance of composite skills in the beginner of the fencing, Journal of Science and Arts, Faculty of Physical Education for Girls, Helwan University.

5- Barnes-Svarney, Patricia L., Svarney, Thomas E. (2016): The Handy Anatomy Answer Book: Includes Physiology, Visible Ink Press, p91-90 .

6- Christie, J. (2011) : "Progressive resistance strength training for improving physical function in older adults", International Journal of older People Nursing, 6 (3): 24446.

7- Fawzi Al-Khodary(2007): Sports Medicine and Fitness, Arab Science House, Lebanon.

8- Gdyczynski C.M., Manbachi A. (2014): "On estimating the directionality distribution in pedicle trabecular bone from micro-CT images", Journal of Physiological Measurements, 35 (12): 2415-2428.

9- Gutiérrez L, Roskell N, Castellsague J, Beard S, Rycroft C, et al. (2011): Study of the incremental cost and clinical burden of hip fractures in post-menopausal women in the United Kingdom. J Med Econ 14: 99-107.

10- Hall, John (2011) : Textbook of Medical Physiology (12th), Philadelphia: Elsevier. p960-957 .

11- Kelly R. et al. (2012) : Effects of a lower limb functional exercise program aimed at minimizing knee valgus angle on running kinematics in youth athletes, Physical Therapy in Sport, P 11-15.

12- Keuerleber J. \& Henschke N. (2012) : "Progressive resistance strength training can reduce physical disability in older adults", British Journal of Sports Medicine. 46 (5): 323-24.

13- Klika, Brett; Jordan, Chris (2013): "High-Intensity Circuit Training Using Body Weight: Maximum Results With Minimal Investment", ACSM's Health \& Fitness Journal, 17 (3): 8-13.

14- Levrero F., Margetts L. (2016): "Evaluating the macroscopic yield behaviour of trabecular bone using a nonlinear homogenisation approach", Journal of the Mechanical Behavior of Biomedical Materials. 61: 384396.

15- Mahan L. K. , Escott-Stump S (2004): Krause's Nutrition and Diet Therapy, The United States of America : Elsevier, Page 123-126. 
16 - Mufti Ibrahim Hammad (2000): Foundations of the development of muscle strength resistors for children in the elementary and preparatory stages, the book center for publishing, Cairo.

17- Mustafa Atwa Soliman(2016): Effect of the rehabilitation program using electric impulses and therapeutic feeding for the treatment of lower back pain in the elderly ,Benha University, Faculty of Physical Education.

18- Owais Ahmed Al-Jabali(2000): Mathematical Training "Theory and Practice", GMS Publishing House, Cairo.

19- Mohammad Al-Rouby(2005): Principles of training in wrestling sport, Mahi for computer services, Alexandria.

20- Peterson, M. D.; Gordon, P. M. (2011) : "Resistance Exercise for the Aging Adult: Clinical Implications and Prescription Guidelines". The American Journal of Medicine. 124 (3): 194-98.

21 - Raymond, Melissa J.; Bramley-Tzerefos, Rebecca E.; Jeffs, Kimberley J.; Winter, Adele; Holland, Anne E. (2013): "Systematic Review of High-Intensity Progressive Resistance Strength Training of the Lower Limb Compared With other Intensities of Strength Training in older Adults", Archives of Physical Medicine and Rehabilitation, 94 (8): 1458-72.

22-Saladin, Kenneth (2012): Anatomy and Physiology: The Unity of Form and Function, McGraw-Hill. p217 .

23- Shaw, I.; Shaw, B.S. (2014): Resistance Training and the Prevention of Sports Injuries. In: Hopkins, G. (Ed.). Sports Injuries: Prevention, Management and Risk Factors, Nova Science Publishers, Hauppauge, NY.
24- Silva, Nádia L.; Oliveira, Ricardo B.; Fleck, Steven J.; Leon, Antonio C.M.P.; Farinatti, Paulo (2014) : "Influence of strength training variables on strength gains in adults over 55 years-old: A meta-analysis of dose-response relationships", Journal of Science and Medicine in Sport, 17 (3): 337-44.

25- Antonio Tramullas , OSTEOPOROSIS AND EXERCISE , Aspire Academy Chief of Health Center 25 May, 2014 , https://www.sehatok.com/health/2017/7/4

26- Chen J, Lin S, Liu C (2014): "Sulfasalazine for ankylosing spondylitis.". The Cochrane database of systematic reviews. doi:10.1002/146558..pub3. PMID 25427435.

27 -"Healthy bones for a lifetime", www.mayoclinic.org,9-3-2017 ، Retrieved 31-7-2018.

28- "Bone health: Tips to keep your bones healthy", www.mayoclinic.org, 15-1-2016 ،Retrieved 31-7-2018.

Franziska Spritzler (18-1-2017),

29 - "10 Natural Ways to Build Healthy Bones" , www.healthline.com, Retrieved 31-7-2018. 30- Bertazzo S, Bertran C.A.(2006): "Morphological and Dimensional Characteristics of Bone Mineral Crystals" , Key Engineering Materials. 309-311: 3. doi:10.4028/www.scientific.net/KEM.309-311.3.

31- Rizzoli R, Chevalley T, Slosman DO, Bonjour JP :Sodium monofluoro phosphate increases vertebral bone mineral density in patients with corticosteroid-induced osteoporosis , Primary study , Journal »Osteoporosis international : a journal established as result of cooperation between the European Foundation for Osteoporosis and the National Osteoporosis Foundation of the USA. 